\title{
Knowledge of childhood blindness among mothers visiting a children's hospital in the kumasi metropolis, Ghana
}

\begin{abstract}
Aim: To determine the knowledge of childhood blindness among mothers visiting a children's hospital in the Kumasi metropolis, Ghana.

Methods: This hospital-based cross-sectional study was conducted from January to March, 2017. One hundred (100) mothers who visited the Asokwa Children's hospital were conveniently sampled for this study. A structured questionnaire was used to collect data on demographics, knowledge on childhood blindness and their causes, childhood blindness prevention and treatment and sources of knowledge. Data were entered and analyzed by IBM SPSS Statistics (version 23). Binary logistic regression models were used to identify associated factors. Odds ratios with $95 \%$ Confidence interval were computed to assess the strength and significant level of associations.
\end{abstract}

Results: The mean age $( \pm \mathrm{SD})$ of the sampled mothers was $32.31( \pm 5.56)$ years. The study showed that 76 (76\%) mothers had good knowledge about childhood blindness. 'Ocular injuries' was the most identified disease that could cause childhood blindness, with 'hereditary retinal dystrophies' being the least. The main source of maternal knowledge on childhood blindness was during pregnancy care (55\%: antenatal and postnatal care). Mothers' educational level was the only factor that significantly influenced maternal knowledge of childhood blindness $(\mathrm{p}<0.001)$

Conclusion: Maternal knowledge about childhood blindness was high. However, intervention modalities that focus on increasing level of parental education, access to antenatal and postnatal care services, and promoting girl-child education should be promoted to help continually raise awareness and knowledge of childhood blindness.

Keywords: childhood blindness, ophthalmia neonatorum, educational level, antenatal care, postnatal care
Volume 7 Issue $3-2017$

\author{
David Ben Kumah, Mohammed Abdul-Kabir, \\ Emmanuel Kobia-Acquah, Martin Adjei \\ Amponsah, Reynolds Kwame Ablordeppey, \\ Ivon Walier Nuo-Ire Kuutiero, Bernice \\ Appiah Ankrah
}

Department of Optometry and Visual Science, Kwame Nkrumah University of Science and Technology, Ghana

\author{
Correspondence: David Ben Kumah, Department of \\ Optometry and Visual Science, Kwame Nkrumah University of \\ Science and Technology, Kumasi, Ghana, \\ Email ben56kay@gmail.com
}

Received: July 21, 2017 | Published: August 08, 2017
Abbreviations: ANC, antenatal care; PNC, postnatal care; OR, odds ratios; CI, confidence interval

\section{Introduction}

Childhood blindness is defined as best corrected visual acuity in the better eye of less than $3 / 60$ in those less than 16 years of age. ${ }^{1}$ In 2010 , there was an estimated 1.26 million blind children globally with majority living in the poor regions of Africa and Asia. ${ }^{2}$ Since 2000, the United Nations' Millennium Development Goals have laid emphasis on the need to promote child health and survival. ${ }^{3}$ From the time when VISION 2020 was launched in 1999, controlling blindness in children has been an important priority. ${ }^{4}$ Childhood blindness has a significant impact on children's health, education and quality of life. ${ }^{5-7}$ The loss of income and productivity associated with a lifetime of blindness are costly for the individual children, their families, community and the government. ${ }^{8}$ The pattern of causes of childhood blindness varies widely between and within countries. Poor countries have corneal scarring (from vitamin A deficiency and measles), ophthalmia neonatorum and harmful traditional practices as the major causes of childhood blindness. Middle income countries have retinal conditions mainly hereditary, retinal dystrophies and retinopathy of prematurity as the major causes of childhood blindness and high income countries have congenital anomalies, visual pathway disorders and retinal conditions as the major causes of childhood blindness. ${ }^{6,9-11}$
The World Health Organization estimates that globally, 80 percent of all blindness is preventable. ${ }^{11}$ The estimated number of blind children in Africa was 419,000 and many more are known to be visually impaired. ${ }^{2}$ It has been reported that approximately 50 percent of childhood blindness in Africa is preventable or treatable through vitamin A supplementation, immunization, refractive interventions and surgery to preserve vision or to restore sight. ${ }^{12}$ Although significant strides have been made in child health in general, the health situation for children in many African countries including Ghana still remains a major concern. Despite the fact that there is a decreasing trend of childhood blindness globally, in Sub-Saharan Africa, there is however a relative increase in the number of blind children: a 40 percent increase in the number of blind children was reported over the last twelve years; from 300,000 in 1999 to 419,000 in $2010 .^{4-6}$

Reducing the incidence of childhood blindness in Sub-Saharan Africa will be furthered if mothers' knowledge regarding the neonatal danger signs of childhood blindness is good enough to make decision to seek appropriate and available healthcare services. Mothers are the closest persons to neonates and that allows them to identify changes in their children's eye health. ${ }^{13,14}$ When mothers receive information about the importance of balanced diet and primary immunizations such as measles, it will help in preventing nutritional blindness. ${ }^{15}$ Literacy and skills training for women not only help them access information about available eye care services, but also equip them with 
the knowledge to educate their children with regards to eye care and eye hygiene. ${ }^{16}$ There are limited published findings on the knowledge of mothers on childhood blindness in Ghana. Such information and findings on maternal knowledge of childhood blindness is necessary in developing proper national strategies aimed at reducing the number of blind children and providing the needed support for them. Thus, this study was aimed at determining the level of maternal knowledge on childhood blindness in a Children's Hospital in the Kumasi metropolis of Ghana.

\section{Methods}

\section{Study design and sampling}

This was a hospital-based cross-sectional study involving 100 mothers visiting the Asokwa Children's Hospital in Kumasi, Ghanafrom January to March, 2017. Convenience sampling technique was used to select the study units.

\section{Data collection}

The study employed only primary sources of data. Data collection involved administration of structured questionnaires to the mothers who visited the Children's Hospital. The questionnaire elicited data on the following: demographics, knowledge on childhood blindness and their causes, childhood blindness prevention and treatment and sources of knowledge.

\section{Data analysis}

The total number of correct responses to 11 items (score of 0 and 1 for incorrect and correct response respectively) was used to measure knowledge of women about conditions that can cause childhood blindness. Women were considered as having good knowledge about childhood blindness when they:

i. Have heard of childhood blindness before,

ii. Know at least four of the enlisted diseases that they could lead to blindness in children,

iii. Know the preventability of certain causes of childhood blindness and mentioning at least one preventive measure and

iv. Know the treatability of certain causes of childhood blindness and mentioning at least one treatment measure.

Data was entered into and analyzed by IBM SPSS Statistics for Windows version 23 (IBM Corp., Armonk, NY, USA). Descriptive statistics were used to describe the study population in relation to relevant variables. Binary logistic regression models were fitted to identify socio-demographic factors that affected mothers' knowledge of childhood blindness. Odds ratios (OR) with 95\% Confidence Interval (CI) at a significance level set at $\mathrm{p}<0.05$ were used to identify these significant factors.

\section{Ethical consideration}

The study was approved by the Department of Optometry and Visual Science, Kwame Nkrumah University of Science and Technology. Permission was sought from the authorities of the Asokwa Children's Hospital. Informed consent was also obtained from the mothers after the purpose of the study had been explained to them. Participants were assured of confidentiality and anonymity of the data they provided. The study was carried out in accordance with the tenets of the Declaration of Helsinki.

\section{Results}

The mean age $( \pm \mathrm{SD})$ of the sampled mothers was $32.31( \pm 5.56)$ years (range $=25,20-45$ years). Most of the mothers were married, economically active and had secondary school education as their highest level of education. Further details of the demographic profiles of the mothers are shown in Table 1. Among the study subjects, 93 (93\%) had heard about childhood blindness. Upon listing eleven diseases/conditions that could lead to childhood blindness, all the 100 $(100 \%)$ mothers had heard of at least two of the diseases. However, only $78(78 \%)$ had heard of more than three of the listed diseases/ conditions that could lead to blindness. Overall, Seventy- six (76\%) mothers were classified as having good knowledge about childhood blindness. 'Ocular injuries' was the most identified condition that could cause childhood blindness, with 'hereditary retinal dystrophies' being the least. Details are shown in Figure 1.

Table I Demographic characteristics of the study subjects

\section{Number (\%)}

\begin{tabular}{ll} 
Age Groups & \\
\hline $20-24$ years & $8(8)$ \\
$25-29$ years & $24(24)$ \\
$30-34$ years & $33(33)$ \\
$35-40$ years & $31(31)$ \\
$>$ 40 years & $4(4)$ \\
Marital Status & \\
Single & $3(3)$ \\
Married & $37(97)$ \\
Occupation & 97 \\
House wife & $3(3)$ \\
Government employee & $39(19)$ \\
Private employee & $21(21)$ \\
Trader & $21(57)$ \\
Ethnicity & 57 \\
Akan & $65(65)$ \\
Ga-Adangbe & 65 \\
Ewe & $4(4) 4$ \\
Northern Tribe & $12(12)$ \\
Educational Level & $12(19)$ \\
No formal education & 19 \\
Primary/Elementary & $9(9)$ \\
Secondary & $17(17)$ \\
Tertiary & $44(44)$ \\
Religion & $44(30)$ \\
Christianity & 30 \\
Islam & $78(78)$ \\
Traditional & $78(16)$ \\
Others & $26(2)$ \\
\hline & $2(4)$ \\
\hline & 4 \\
\hline
\end{tabular}




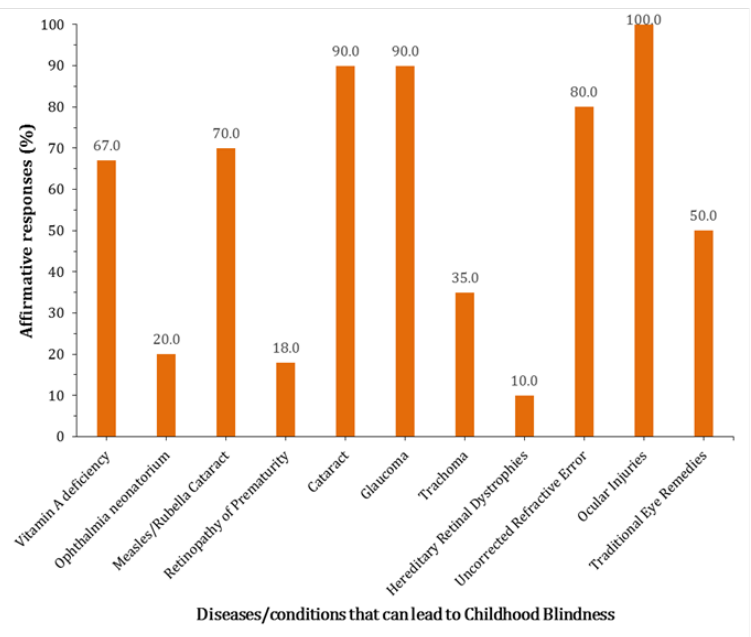

Figure I Knowledge on Causes of childhood blindness.

Ninety-seven $(97 \%)$ mothers knew that some of the causes of childhood blindness could be prevented and 95 of them (97.9\%) were able to mention at least one correct preventive measure. Again, all mothers knew that at least one of the causes of childhood blindness was treatable and were able to mention at least one treatable measure. The main sources of maternal knowledge on childhood blindness ranged from electronic media to pregnancy care antenatal care (ANC) and postnatal care (PNC) (Figure 2). Logistic regression models showed mothers' educational level was the factor that significantly affected maternal knowledge about childhood blindness $(\mathrm{p}<0.001)$ The mothers who have completed primary/elementary school education were at least three times ( $\mathrm{OR}=3.11,95 \%$ CI: 1.04-19.52) more likely to have 'good knowledge' about childhood blindness than mothers who have never been to school. Again, mothers who have completed secondary school education were five times $(\mathrm{OR}=5.06$, 95\% CI: 1.49-17.19) more likely to have 'good knowledge' about childhood blindness than mothers who have completed only primary/ elementary school.

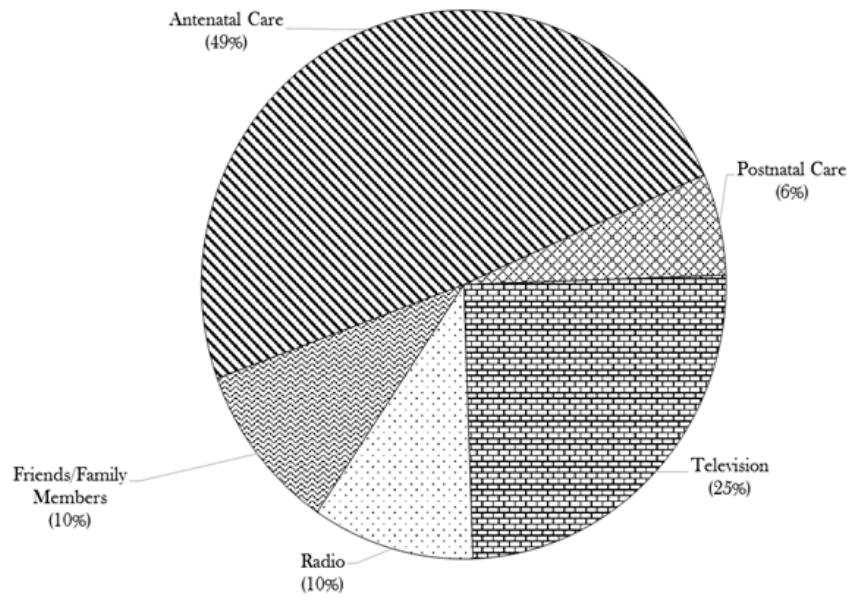

Figure 2 Sources of maternal knowledge on childhood blindness.

\section{Discussion}

Prevention and/or reduction of childhood blindness is near impossible without good maternal knowledge regarding this deleterious condition. This study presented the level and identified the contributing factors for good maternal knowledge on childhood blindness among mothers who visited a Children's Hospital in Kumasi, Ghana. The results from this study showed high maternal awareness and knowledge of childhood blindness. The level of good maternal knowledge (76\%) of childhood blindness was significantly higher than the level of maternal knowledge of neonatal danger signs ${ }^{17}$ and childhood acute respiratory infections in Ghana. ${ }^{18}$ This may likely be due to the increased national education through the electronic and print media (eg. special column in national newspaper, radio programs and use of social media) on ocular conditions in a bid to achieve the VISION 2020 goals. Ocular injury is a major cause of unilateral childhood blindness in children. ${ }^{19-21}$ Most of these injuries (mostly from broomsticks, stones and glass) occur during recreational games at home..$^{22-24}$ Thus, it was not surprising all mothers were able to identify that 'ocular injuries' can result in childhood blindness. Ghana's expanded immunization and vitamin A supplementation programmes and health reforms may have accounted for the relatively high maternal awareness of 'rubella' and 'vitamin A deficiency' as potential causes of blindness. ${ }^{25}$ Relatively low identification of 'retinopathy of prematurity' and 'hereditary retinal dystrophies' were expected as most of these conditions are relatively uncommon causes of childhood blindness in Ghana. ${ }^{6,9-11,26}$ Since these causes are less prevalent in Ghana, less education is likely to be given on them during pregnancy care and in the mass media. Conversely, most study participants were aware of the other major causes of childhood blindness in Africa: cataract, glaucoma, uncorrected refractive error and traditional eye remedies. ${ }^{12}$

This study also showed a relatively high proportion of mothers who knew of treatment and/or preventive measures for diseases that can result in childhood blindness. Our results is higher compared to that reported by Ramai \& Pulisetty ${ }^{13}$ among mothers and female caregivers. Although our study is in a similar study area and has similar study participants as that of Ramai \& Pulisetty, ${ }^{13}$ the discrepancy in knowledge of eye disease prevention could be due to the differences in study design: a hospital-based study to a community-based study. Sources of information on childhood blindness were similar to that of sources of knowledge of eye care services and personnel reported by Ovenseri-Ogbomo et al., ${ }^{27}$ in a similar cosmopolitan city in Ghana. A major source of knowledge for the study participants was during pregnancy care (55\%: ANC and PNC). This agrees with the findings of Nigatu et al., ${ }^{28}$ and therefore highlights ANC and PNC as important opportunities for educating mothers about the general and ocular health of themselves and their wards.

Similar to various researches that assessed maternal knowledge on various paediatric conditions: childhood immunization, ${ }^{29}$ child development, ${ }^{30}$ neonatal danger signs, ${ }^{28}$ child survival, ${ }^{31}$ childhood diarrhoea and diet, ${ }^{32,33}$ and childhood acute respiratory infections, ${ }^{18}$ our results showed education significantly influenced maternal knowledge. None of the uneducated (never been to school) participants had good knowledge about childhood blindness. Majority of and all mothers who had completed secondary school and tertiary education respectively had good knowledge about childhood blindness. Furthermore, our results showed that the higher the level of education, the more likely the mother will have better knowledge about childhood blindness. Thus demonstrating maternal education and literacy levels were directly proportional to the level of their awareness or knowledge..$^{34,35}$ A possible explanation for this finding is that educated mothers are more likely to use health facilities to obtain 
information about various medical conditions and health pertaining to their children. ${ }^{36}$ Educated women are also more likely to be proactive in searching for information on their children's health from qualified personnel, internet and/or other forms of media. ${ }^{14}$ On the contrary, maternal occupation, marital status, occupation, ethnicity and religion did not have any influence on the maternal knowledge on childhood blindness, similar to that reported by Mwambete \& Joseph. ${ }^{35}$

\section{Conclusion}

The findings indicated high maternal knowledge and practices concerning childhood blindness. Although this is positive, there should be continual efforts to educate the mothers, caregivers and the general public through ANC, PNC, health personnel and the mass media. Maternal educational level was the only socio-demographic factor associated with good maternal knowledge. As such, efforts should be made to promote girl-child education in the country.

\section{Acknowledgements}

We would like to acknowledge administrative bodies at all levels who endorsed us to undertake this study. Authors gratefully thank study participants and data collectors who actively participated in this research work

\section{Conflicts of interest}

There are no conflicts of interest.

\section{Funding}

None.

\section{References}

1. Mabey D, Gill G, Weber MW. Principles of Medicine in Africa: Cambridge University Press; 2013.

2. Quinn G, Gilbert CE. Supporting collaborations to prevent blindness in children in resource-poor settings. Experts Review of Ophthalmology. 2014;6(3):287-290.

3. Faal HB. Millennium development goals and eye health. Indian $J$ Ophthalmol. 2012;60(50):411-415.

4. World Health Organization. Preventing blindness in children. WHO/ PBL/00.77. WHO, Geneva: Switzerland; 1999.

5. Chandna A, Gilbert C. When your eye patient is a child. Community Eye Health. 2010;23(72):1-3.

6. Gilbert C, Foster A. Childhood blindness in the context of VISION 2020 - The right to sight. Bull World Health Organ. 2001;79(3):227-232.

7. Bronsard A, Geneau R, Shirima S, et al. Why are children brought late for cataract surgery? Qualitative findings from Tanzania. Ophthalmic Epidemiology. 2008;15(6):383-388.

8. Frick KD, Foster A. The magnitude and cost of global blindness: an increasing problem that can be alleviated. Am J Ophthalmol. 2003;135(4):471-476.

9. Kocur I, Resnikoff S. Visual impairment and blindness in Europe and their prevention. Br J Ophthalmol. 2002;86(7):16-722.

10. Gogate $\mathrm{P}$, Kalua $\mathrm{K}$, Courtright $\mathrm{P}$. Blindness in Childhood in Developing Countries: Time for a Reassessment? PLoS Med. 2009;6(12):e1000177.

11. World Health Organization. Priority eye diseases. Retrieved 6th June. 2016.
12. Solarsh G, Hofman KJ. Developmental Disabilities. In: Jamison DT, Feachem RG, editors. Disease and Mortality in Sub-Saharan Africa. $2^{\text {nd }}$ ed. Washington (DC), USA: The International Bank for Reconstruction and Development/The World Bank. Chapter 10.

13. Ramai D, Pulisetty T. Maternal and Caregiver Perceptions to Childhood Eye Care In Ghana. The Internet Journal of Epidemiology. 2013;11(1):1.

14. Dongre AR, Deshmukh PR, Garg BS. Perceptions and health care seeking about newborn danger signs among mothers in rural Wardha. Indian Journal of Pediatrics. 2008;75(4):325-329.

15. Sandiford P, Cassel J, Montenegro M, et al. The Impact of Women's Literacy on Child Health and its Interaction with Access to Health Services. Population Studies. 1995;49(1):5-17.

16. Grown C, Gupta GR, Pande R. Taking action to improve women's health through gender equality and women's empowerment. Lancet. 2005;365(9458):541-543.

17. Hill Z, Kendall C, Arthur P, et al. Recognizing childhood illnesses and their traditional explanations: exploring options for care-seeking interventions in the context of the IMCI strategy in rural Ghana. Trop Med Int Health. 2003;8(7):668-676.

18. Denno DM, Bentsi-Enchill A, Mock CN, et al. Maternal knowledge, attitude and practices regarding childhood acute respiratory infections in Kumasi, Ghana. Ann Trop Paediatr. 1994;14(4):293-301.

19. Thylefors B. Geneva: World Health Organisation. Ocular trauma. In: Strategies for Prevention of Blindness in National Programmes - A Primary Health Care Approach. 1997. p. 74-80.

20. Thylefors B. Epidemiological patterns of ocular trauma. Australian and New Zealand Journal of Ophthalmology. 1992;20(2):95-98.

21. Lithander J, Al Kindi H, Tönjum AM. Loss of visual acuity due to eye injuries among 6292 school children in the Sultanate of Oman. Acta Ophthalmologica Scand. 1999;77(6):697-699.

22. Ukponmwan $\mathrm{CU}$, Momoh RO. Broomstick Injuries to the Eye; an Emerging Cause of Blindness among Children in Nigeria. Niger J Surg. 2015;21(1):13-17.

23. Koutures CG, Gregory AJ. Injuries in youth soccer. Pediatrics. 2010;125(2):410-414.

24. Gatsey PSN, Tchiakpe MP, Kumah DB, et al. Paediatric Ocular Injuries Associated with Ghanaian Recreational Activities in the Ashaiman Municipality, Ghana. JOJ Ophthalmology. 2017;3(3):555615.

25. WHO Ghana. A profile: Expanded programme on immunization in Ghana, 2016.

26. Kong L, Fry M, Al-Samarraie M, et al. An update on progress and the changing epidemiology of causes of childhood blindness worldwide. Journal of American Association for Pediatric Ophthalmology and Strabismus. 2012;16(6):501-507.

27. Ovenseri-Ogbomo GO, Afful O, Kio FE. Eye care utilisation among slum dwellers in the greater Accra region, Ghana. East African Medical Journal. 2011;88(7):219-228.

28. Nigatu SG, Worku AG, Dadi AF. Level of mother's knowledge about neonatal danger signs and associated factors in North West of Ethiopia: a community based study. BMC Research Notes. 2015;8:309.

29. Vonasek BJ, Bajunirwe F, Jacobson LE, et al. Do Maternal Knowledge and Attitudes towards Childhood Immunizations in Rural Uganda Correlate with Complete Childhood Vaccination? PLoS One. 2016;11(2):e0150131.

30. Gewa CA, Chepkemboi J. Maternal knowledge, outcome expectancies and normative beliefs as determinants of cessation of exclusive 
breastfeeding: a cross-sectional study in rural Kenya. BMC Public Health. 2016;(16):243.

31. Amare D, Dereje B, Kassie B, et al. Maternal Knowledge and Practice Towards Diarrhoea Management in Under Five Children in Fenote Selam Town, West Gojjam Zone, Amhara Regional State, Northwest Ethiopia, 2014. Journal of Infectious Diseases and Therapy. 2014;2:182.

32. Datta V, John R, Singh VP, et al. Maternal knowledge, attitude and practices towards diarrhea and oral rehydration therapy in rural Maharashtra. Indian Journal of Pediatrics. 2001;68(11):1035-1037.

33. Khalili M, Mirshahi M, Zarghami A, et al. Maternal Knowledge and Practice Regarding Childhood Diarrhea and Diet in Zahedan, Iran. Health Scope. 2013;2(1):19-24.
34. Ketsela T, Asfaw M, Belachew C. Knowledge and practice of mothers care-takers towards diarrhoea and its treatment in rural communities in Ethiopia. Ethiop Med J. 1991;9(4):213-224.

35. Mwambete KD, Joseph R. Knowledge and perception of mothers and caregivers on childhood diarrhoea and its management in Temeke municipality, Tanzania. Tanzan J Health Res. 2010;12(1):47-54.

36. Buor D. Mothers' education and childhood mortality in Ghana. Health Policy. 2003;64(3):297-309. 